\title{
Naturally Occurring Fusarium Species and Mycotoxins in Oat Grains from Manitoba, Canada
}

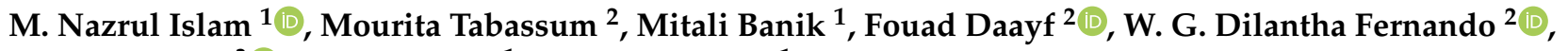 \\ Linda J. Harris ${ }^{3}{ }^{\circledR}$, Srinivas Sura ${ }^{1}$ and Xiben Wang ${ }^{1, *}$ \\ 1 Agriculture and Agri-Food Canada (AAFC), Morden Research and Development Centre, 101 Route 100, \\ Morden, MB R6M 1Y5, Canada; naz.islam@agr.gc.ca (M.N.I.); mitali.banik@agr.gc.ca (M.B.); \\ srinivas.sura@agr.gc.ca (S.S.) \\ 2 Department of Plant Science, University of Manitoba, 66 Dafoe Road, Winnipeg, MB R3T 2N2, Canada; \\ tabassu3@myumanitoba.ca (M.T.); fouad.daayf@umanitoba.ca (F.D.); \\ dilantha.fernando@umanitoba.ca (W.G.D.F.) \\ 3 Agriculture and Agri-Food Canada (AAFC), Ottawa Research and Development Centre, 960 Carling Avenue, \\ Ottawa, ON K1A 0C6, Canada; linda.harris@agr.gc.ca \\ * Correspondence: xiben.wang@agr.gc.ca
}

Citation: Islam, M.N.; Tabassum, M.; Banik, M.; Daayf, F.; Fernando, W.G.D.; Harris, L.J.; Sura, S.; Wang, X. Naturally Occurring Fusarium Species and Mycotoxins in Oat Grains from Manitoba, Canada. Toxins 2021, 13, 670. https://doi.org/10.3390/ toxins 13090670

Received: 30 August 2021

Accepted: 16 September 2021

Published: 18 September 2021

Publisher's Note: MDPI stays neutral with regard to jurisdictional claims in published maps and institutional affiliations.

\begin{abstract}
Fusarium head blight (FHB) can lead to dramatic yield losses and mycotoxin contamination in small grain cereals in Canada. To assess the extent and severity of FHB in oat, samples collected from 168 commercial oat fields in the province of Manitoba, Canada, during 2016-2018 were analyzed for the occurrence of Fusarium head blight and associated mycotoxins. Through morphological and molecular analysis, F. poae was found to be the predominant Fusarium species affecting oat, followed by F. graminearum, F. sporotrichioides, F. avenaceum, and F. culmorum. Deoxynivalenol (DON) and nivalenol (NIV), type B trichothecenes, were the two most abundant Fusarium mycotoxins detected in oat. Beauvericin (BEA) was also frequently detected, though at lower concentrations. Close clustering of F. poae and NIV/BEA, F. graminearum and DON, and F. sporotrichioides and HT2/T2 (type A trichothecenes) was detected in the principal component analysis. Sampling location and crop rotation significantly impacted the concentrations of Fusarium mycotoxins in oat. A phylogenetic analysis of $95 \mathrm{~F}$. poae strains from Manitoba was conducted using the concatenated nucleotide sequences of Tef- $1 \alpha$, Tri1, and Tri8 genes. The results indicated that all F. poae strains belong to a monophyletic lineage. Four subgroups of F. poae strains were identified; however, no correlations were observed between the grouping of F. poae strains and sample locations/crop rotations.
\end{abstract}

Keywords: Fusarium head blight; oats; mycotoxins; chemotypes; phylogenetic analysis

Key Contribution: Identification of Fusarium species spectrum and main Fusarium chemotypes associated with FHB on oat in Canada; profiling naturally occurring Fusarium mycotoxins in oat grains and main contributors of these mycotoxins.

\section{Introduction}

Canada is one of the world's leading countries in the production and export of high-quality oat (Avena sativa L.), accounting for $15 \%$ of total global production and approximately $60 \%$ of global exports [1]. Oat is grown for both feed and food in Canada. In recent years, the use of oat and processed oat products for human consumption has increased by approximately $5 \%$ on an annual basis due to its unique nutritional benefits, such as high $\beta$-glucan content, high protein content, and healthy lipid profile [1,2].

Fusarium head blight (FHB) is a severe production problem for wheat (Triticum aestivum L.) and barley (Hordeum vulgare L.) producers in North America. In comparison, oat has been considered as a less susceptible host to FHB; this is mainly attributed to the lack of visual symptoms on infected panicles and long pedicels between spikelets that 
prevent the spread of fungal mycelia throughout the panicle [3,4]. However, oat grains can accumulate considerable amounts of Fusarium mycotoxins. FHB on oats in western Canada was first identified during the FHB epidemic in 1993. Since then, the sporadic and localized presence of FHB on oat has been reported in both western and eastern provinces of Canada [4-7]. A gradual increase in the incidence of FHB on oat in Canada has been documented in recent years; however, a severe FHB outbreak in oat has not yet been recorded [8].

FHB is caused by several species of fungi in the genus Fusarium. F. graminearum (Schwabe) and F. poae (Peck) Wollenw. are the principal Fusarium species causing FHB on oat in the prairie and eastern provinces of Canada. Several other species, including F. sporotrichioides Sherb., F. avenaceum (Fr.) Sacc., F. culmorum (W.G. Smith) Sacc., and F. equiseti (Corda) Sacc., are isolated from oat grains but at much lower frequencies $[5,8]$. F. graminearum is recognized as the most virulent species and the principal causal agent of FHB worldwide, including in Canada $[9,10]$. F. poae is generally regarded as a weak pathogen to cereals; however, it is the most frequently isolated Fusarium pathogen in several cereal disease surveys conducted across South American and European countries [11,12]. Additionally, F. sporotrichioides was also recognized as one of the causative agents of FHB in temperate regions of Europe [13].

FHB-infected cereal grains are often contaminated with mycotoxins that are toxic to animals and humans. Fusarium species can produce multiple mycotoxins. F. graminearum is a potent producer of deoxynivalenol (DON), the mycotoxin most commonly detected in cereal grains in Canada. DON is known to induce toxicity by inhibiting protein synthesis in both humans and animals $[10,13]$. F. poae can produce both trichothecene mycotoxins, including diacetoxyscirpenol (DAS), monoacetoxyscirpenol (MAS), scirpentriol (STO), nivalenol (NIV), fusarenone-X (FX), and non-trichothecene mycotoxins, such as beauvericin (BEA) $[12,14,15]$. NIV is the most documented mycotoxin produced by F. poae $[14,16]$. It is lymphotoxic to human B and T cells and can also induce apoptosis in human promyelocytic leukemia cells [17]. In Europe, T-2 and HT-2 are trichothecenes commonly detected in oat. They are potent cytotoxic and immunosuppressive agents that can cause acute intoxication and chronic diseases in both humans and animals [13]. An outbreak of alimentary toxic aleukia due to T-2/HT-2 contamination killed thousands of people in Russia in the 1940s [18]. F. langsethiae and F. sporotrichioides are potent producers of T-2 and HT-2 [19]. In Scandinavian countries, F. langsethiae is the main contributor to the accumulation of these mycotoxins in oat grains [20]. However, to the best of the authors' knowledge, this pathogen has not been identified in Canada.

The multi-species nature of FHB on oat significantly impacts current management practices for this disease. F. avenaceum, F. langsethiae, and F. poae are more tolerant to ergosterol-biosynthesis-inhibiting azole fungicides than F. graminearum [21]. Evidence suggests the efficacy of fungicides and biological control treatments against F. graminearum is reduced when other Fusarium pathogens co-occur at infection sites [22]. Furthermore, the application of certain fungicides may lead to an increased share of other Fusarium species in the FHB population at the expense of F. graminearum [23]. A detailed understanding of the spectrum of Fusarium species associated with FHB in oat and the naturally occurring mycotoxins associated with these pathogens is urgently needed to prevent crop contamination.

To investigate the prevalence of FHB on oat and the disease complexity in terms of species and mycotoxin profiles, we analyzed oat samples collected from commercial fields from 2016 to 2018. Our study aimed to investigate: (i) Fusarium species spectrum and main Fusarium chemotypes associated with FHB in oat; (ii) the profile of naturally occurring Fusarium mycotoxins in oat grains and main contributors of these mycotoxins; (iii) the phylogenetic relationship of a collection of F. poae strains from Manitoba; (iv) the impact of sample location and crop rotation on mycotoxin levels in oat samples. 


\section{Results}

Due to the lack of typical FHB symptoms on infected oat panicles, Fusarium infection in oat was investigated using the plating method and PCR-based techniques using Fusarium species-specific primers. Five Fusarium species were isolated from oat grains collected in Manitoba in 2016-2018 (Table 1). F. poae was the predominant species, occurring in $68.7 \%$ of fields and $58.7 \%$ of kernels. Infection caused by F. graminearum was also common, detected in $33.7 \%$ of fields and $16.6 \%$ of kernels. In comparison, the infection caused by F. sporotrichioides was less frequent, found in $10.3 \%$ of fields and $14 \%$ of kernels. F. avenaceum and F. culmorum were only sporadically detected (Table 1).

Table 1. Fusarium species complex in oat kernels collected from commercial fields in Manitoba (2016-2018).

\begin{tabular}{|c|c|c|c|c|c|c|c|c|}
\hline \multirow{2}{*}{ Fusarium Species } & \multicolumn{4}{|c|}{$\%$ of Infected Fields } & \multicolumn{4}{|c|}{$\%$ of Infected Kernels } \\
\hline & 2016 & 2017 & 2018 & $\begin{array}{c}\text { Three-Year } \\
\text { Mean }\end{array}$ & 2016 & 2017 & 2018 & $\begin{array}{c}\text { Three-Year } \\
\text { Mean }\end{array}$ \\
\hline F. poae & 72.0 & 65.0 & 69.0 & $68.7 \pm 3.5$ & 61.0 & 62.0 & 53.0 & $58.7 \pm 4.9$ \\
\hline F. graminearum & 28.0 & 25.0 & 48.0 & $33.7 \pm 9.6$ & 22.3 & 14.8 & 12.8 & $16.6 \pm 5.0$ \\
\hline F. sporotrichioides & 9.0 & 7.0 & 15.0 & $10.3 \pm 4.2$ & 8.0 & 22.0 & 12.0 & $14.0 \pm 7.2$ \\
\hline F. avenaceum & 2.3 & 3.3 & 1.3 & $2.3 \pm 11$ & 0.4 & 0.5 & 0.2 & $0.4 \pm 0.2$ \\
\hline F. culmorum & 2.3 & 1.7 & 0.0 & $1.3 \pm 1.2$ & 0.4 & 0.3 & 0.0 & $0.2 \pm 0.2$ \\
\hline $\begin{array}{l}\text { Total no. of } \\
\text { fields / kernels }\end{array}$ & 43 & 60 & 65 & & 2150 & 3000 & 3250 & \\
\hline
\end{tabular}

A PCR-based method was used to verify the spectrum of Fusarium species in oat samples. F. poae was the most frequently detected Fusarium species (59\%), followed by F. graminearum (25\%) and F. sporotrichioides (12\%). These three Fusarium species accounted for $97 \%$ of all detected Fusarium species (Figure 1A). Both 3-ADON and 15-ADON chemotypes of F. graminearum were detected (Figure 1B). F. graminearum 3-ADON strains were detected in $49 \%$ of fields, whereas $15-$ ADON strains were detected in $45 \%$ of fields. We did not detect any F. graminearum strains with the NIV chemotype. However, F. poae strains with the NIV chemotype were detected in 91\% of fields (Figure 1B).

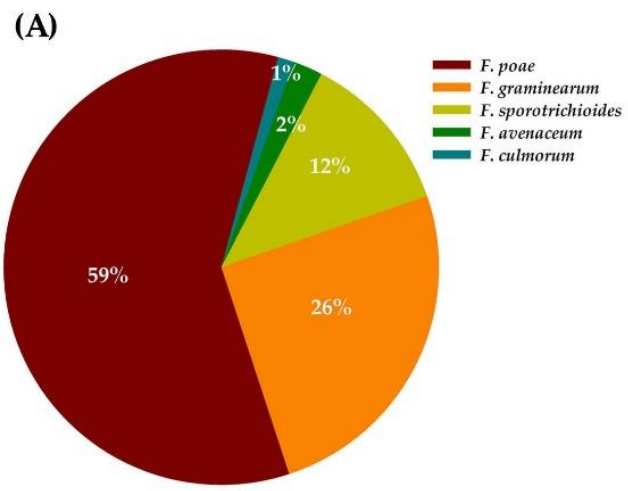

(B)

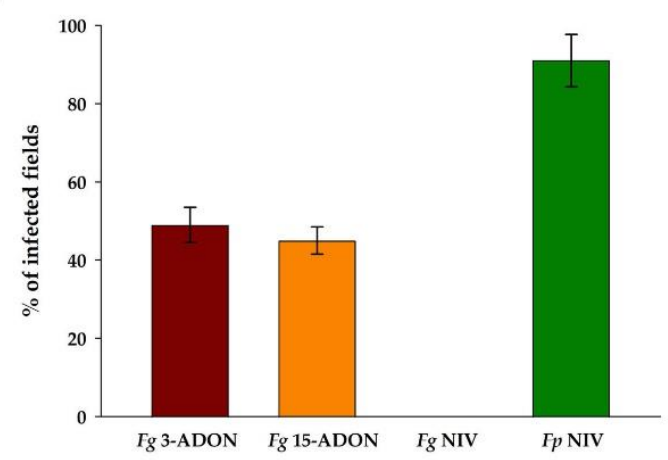

Figure 1. PCR-based characterization of Fusarium species complex associated with Fusarium head blight on oat in Manitoba (2016-2018). (A): Frequencies of Fusarium DNA detected in commercial oat fields in Manitoba; (B): distribution of Fusarium chemotypes in Manitoba oat fields. Number of samples $(n)=168$.

Quantitative PCR (qPCR) was used to quantify the abundance of Fusarium DNA in oat grains (Table 2$)$. Due to low Ct values $(<37)$ in the majority of samples, data for F. avenaceum and F. culmorum were not included (Table 2). The concentration of F. poae DNA in oat samples was the highest (Table 2). For the 2016 and 2017 samples, the concentration of F. poae DNA was two times higher than that of F. graminearum. This result agrees with 
the findings of the morphological analyses. The mean concentration of $F$. graminearum DNA was lower than that of F. poae but significantly higher than for F. sporotrichioides.

Table 2. Quantitative PCR analysis of the abundance of F. poae, F. graminearum, and F. sporotrichioides DNA in oat grains from Manitoba (2016-2018).

\begin{tabular}{|c|c|c|c|c|c|c|}
\hline Year & \multicolumn{2}{|c|}{2016} & \multicolumn{2}{|c|}{2017} & \multicolumn{2}{|c|}{2018} \\
\hline n-Samples/Fields & \multicolumn{2}{|c|}{43} & \multicolumn{2}{|c|}{60} & \multicolumn{2}{|c|}{65} \\
\hline Species & Range & Mean & Range & Mean & Range & Mean \\
\hline F. poae & $0.01-1.58$ * & $\begin{array}{c}0.13 \pm 0.05 \\
a^{* *}\end{array}$ & $0.02-1.35$ & $\begin{array}{c}0.12 \pm 0.07 \\
\mathrm{a}\end{array}$ & $0.00-1.37$ & $\begin{array}{c}0.08 \pm 0.01 \\
\mathrm{a}\end{array}$ \\
\hline F. graminearum & $0.01-1.93$ & $\begin{array}{c}0.05 \pm 0.01 \\
b\end{array}$ & $0.01-0.80$ & $\begin{array}{c}0.07 \pm 0.01 \\
\mathrm{a}\end{array}$ & $0.01-0.31$ & $\begin{array}{c}0.07 \pm 0.01 \\
\mathrm{a}\end{array}$ \\
\hline F. sporotrichioides & $0.01-0.38$ & $\begin{array}{c}0.02 \pm 0.01 \\
\mathrm{~b}\end{array}$ & $0.01-0.05$ & $\begin{array}{c}0.01 \pm 0.01 \\
\mathrm{~b}\end{array}$ & $0.00-0.15$ & $\begin{array}{c}0.01 \pm 0.01 \\
\mathrm{~b}\end{array}$ \\
\hline
\end{tabular}

*The abundance of Fusarium DNA is expressed as pg of Fusarium gDNA/ng of total gDNA. ${ }^{* *}$ Mean \pm SE refers to combining average concentrations of all samples. Means followed by the same letter within the same year are not significantly different at $p=0.05$ based on Student's $t$-test.

Naturally occurring mycotoxins in oat grains were analyzed using an ultra-highperformance liquid chromatography-high-resolution mass spectrometry (UHPLC-HRMS). Deoxynivalenol, NIV, and BEA were the three most common mycotoxins found in oat grains from Manitoba (Table 3). The maximum concentrations of DON in oat samples were 4143,1881 , and $632 \mathrm{ppb}$ in 2016, 2017, and 2018, respectively. The mean concentration of DON was the highest in 2016 (604 ppb) and the lowest in 2018 (253 ppb). NIV was detected in 75 to $100 \%$ of samples, with mean concentrations of 252,234 , and $145 \mathrm{ppb}$ for 2016, 2017, and 2018, respectively. BEA was detected in 70 to $90 \%$ of samples. The mean concentrations of BEA were lower than those of DON and NIV. Contamination of oat grains with T-2, HT-2, Moniliform (MON), DAS, and Enniatins (ENNs) (A, A1, B, and B1) only occurred at very low levels (Table 3).

Table 3. Naturally occurring Fusarium mycotoxins in Manitoba oat grains (2016-2018).

\begin{tabular}{|c|c|c|c|c|c|c|c|c|c|}
\hline \multirow{3}{*}{ N-Samples/Fields } & \multicolumn{3}{|c|}{2016} & \multicolumn{3}{|c|}{2017} & \multicolumn{3}{|c|}{2018} \\
\hline & \multicolumn{3}{|c|}{43} & \multicolumn{3}{|c|}{60} & \multicolumn{3}{|c|}{65} \\
\hline & $\begin{array}{c}\% \text { of Fields } \\
\text { Above LOD }\end{array}$ & $\begin{array}{l}\text { Maximum } \\
(\mu \mathrm{g} / \mathrm{kg})\end{array}$ & $\begin{array}{c}\text { Mean } \\
(\mu \mathrm{g} / \mathrm{kg})\end{array}$ & $\begin{array}{l}\% \text { of Fields } \\
\text { Above LOD }\end{array}$ & $\begin{array}{l}\text { Maximum } \\
(\mu \mathrm{g} / \mathrm{kg})\end{array}$ & $\begin{array}{c}\text { Mean } \\
(\mu \mathrm{g} / \mathrm{kg})\end{array}$ & $\begin{array}{c}\% \text { of Fields } \\
\text { Above LOD }\end{array}$ & $\begin{array}{l}\text { Maximum } \\
(\mu \mathrm{g} / \mathrm{kg})\end{array}$ & $\begin{array}{c}\text { Mean } \\
(\mu \mathrm{g} / \mathrm{kg})\end{array}$ \\
\hline DON & 85 & 4143 & $604 \pm 87$ & 41 & 1881 & $569 \pm 104$ & 40 & 632 & $253 \pm 20$ \\
\hline NIV & 100 & 865 & $252 \pm 27$ & 78 & 795 & $234 \pm 16$ & 98 & 581 & $145 \pm 12$ \\
\hline $\mathrm{T}-2$ & 77 & 1155 & $43 \pm 18$ & 81 & 973 & $53 \pm 16$ & 25 & 794 & $22 \pm 12$ \\
\hline HT-2 & 35 & 1100 & $60 \pm 29$ & 13 & 419 & $26 \pm 10$ & 17 & 654 & $23 \pm 11$ \\
\hline BEA & 90 & 119 & $25 \pm 4$ & 80 & 159 & $41 \pm 4$ & 71 & 169 & $24 \pm 5$ \\
\hline MON & 32 & 349 & $31 \pm 11$ & 20 & 533 & $30 \pm 11$ & 11 & 209 & $12 \pm 5$ \\
\hline DAS & 15 & 25 & $8 \pm 1.1$ & 7 & 25 & $7 \pm 0.6$ & 5 & 25 & $6 \pm 0.5$ \\
\hline ENNs & 43 & 1605 & $65 \pm 6$ & 39 & 93 & $16 \pm 2$ & 17 & 128 & $10 \pm 1$ \\
\hline
\end{tabular}

Note: \% of fields determined by mycotoxin infected fields/total number of fields. Mycotoxins presented here are at concentrations above the limit of quantitation (LOQ) and limit of detection (LOD) of $50 \mu \mathrm{g} / \mathrm{kg}(\mathrm{ppb})$ and $10 \mu \mathrm{g} / \mathrm{kg}(\mathrm{ppb}$ ), respectively. Mycotoxin concentrations below the respective LOQ or LOD were calculated as LOQ/2 or LOD/2, respectively, \pm standard error. ENNs are the sum of ENN A, A1, B, and B1.

Principal component analysis (PCA) was performed to identify the primary contributors of different Fusarium mycotoxins in oats. The first two dimensions accounted for $53 \%$ of the variability using the three most common Fusarium species ( $F p, F g$, and $F s$ ) found in the grain samples. On the $x$-axis, component 1 describes $31 \%$ of the variability; on the $y$-axis, component 2 represents an additional 22\% of the original variability (Figure 2). A strong correlation was found between $F g$ DNA and DON as they clustered in the same quadrant. Similarly, Fp DNA, NIV, and BEA showed a close association. Fs and T-2/HT-2 showed the maximum correlation within 3-year sample analyses (Figure 2). MON, DAS, 
and ENNs were excluded in the correlation analysis due to the low detection rate in the majority of oat samples.

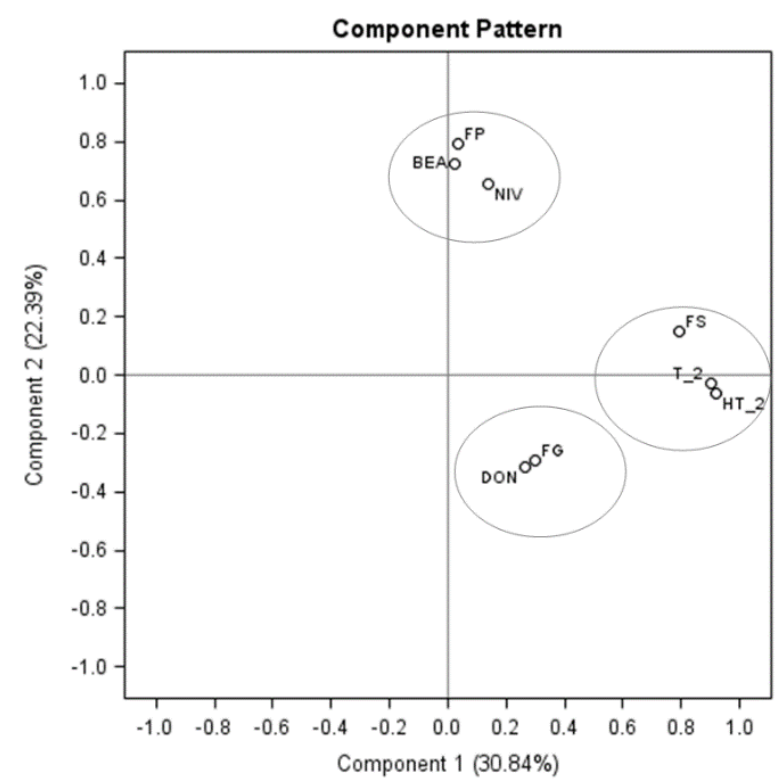

Figure 2. Principal component analysis of the relationship between the abundance of Fusarium DNA (FP: F. poae, FG: F. graminearum, and FS: F. sporotrichioides) and mycotoxin concentrations (NIV, BEA, DON, T-2, and HT-2) in oat grains. The percentages of variance explained by axes/components 1 and 2 are shown in parentheses. Each point represents the mean of 3-year samples $(n=168)$.

We investigated the impact of sampling locations and crop rotation on mycotoxin levels in oat grains. The ANOVA showed sampling location impacted the mean concentrations of DON, NIV, BEA, T-2, and HT-2 (Table 4). The concentration of DON was the highest in samples from Central Manitoba (CMB) and Eastern Manitoba (EMB), and the concentration of NIV was higher in samples from CMB and SWMB (Southwest Manitoba). The average concentration of BEA in samples from CMB and INMB (Interlake Manitoba), T-2 in samples from CMB, and HT-2 in CMB and SWMB were higher compared to other crop districts. Crop rotation also had a significant impact on the mean concentrations of DON, BEA, and T-2 (Table 4). The concentrations of DON, NIV, BEA, and T-2 were the highest in grain samples from fields undergoing cereal (wheat/barley)-oat rotation (Figure 3). However, these toxins were measured at significantly lower levels when canola (Brassica napus L.) or flax (Linum usitatissmum L.) was grown instead of cereal (wheat/barley) as a preceding crop.

Table 4. ANOVA of the effect of sampling location/crop rotation on Fusarium mycotoxin levels in oat samples.

\begin{tabular}{lccccc}
\hline & \multicolumn{5}{c}{ Fusarium Mycotoxin Levels } \\
\cline { 2 - 6 } & \multicolumn{5}{c}{$p$-Value } \\
\hline Source of variation & DON & NIV & BEA & T-2 & HT-2 \\
Sample locations & $*$ & $*$ & $*$ & ns & $*$ \\
Crop rotations & $*$ & ns & $*$ & $*$ & ns \\
\hline
\end{tabular}

${ }^{\dagger} p$-values are marked as $*(p<0.05)$ to assess significant difference between Fusarium mycotoxin levels and sampling locations/crop rotations; ns indicates non-significant. 
(A)

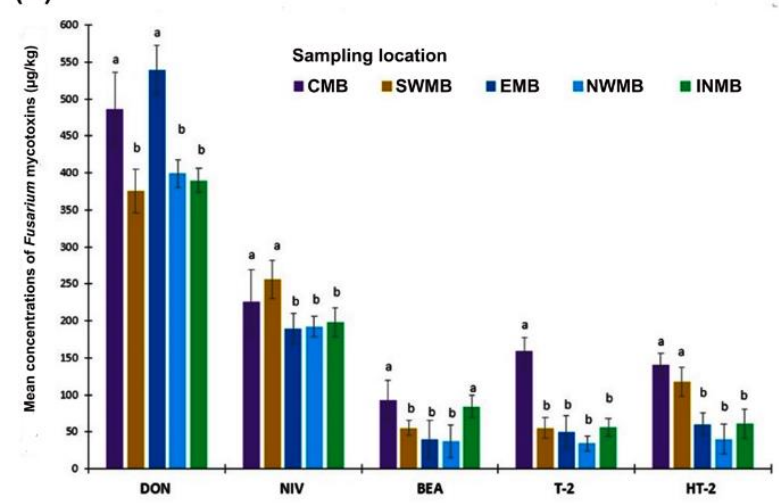

(B)

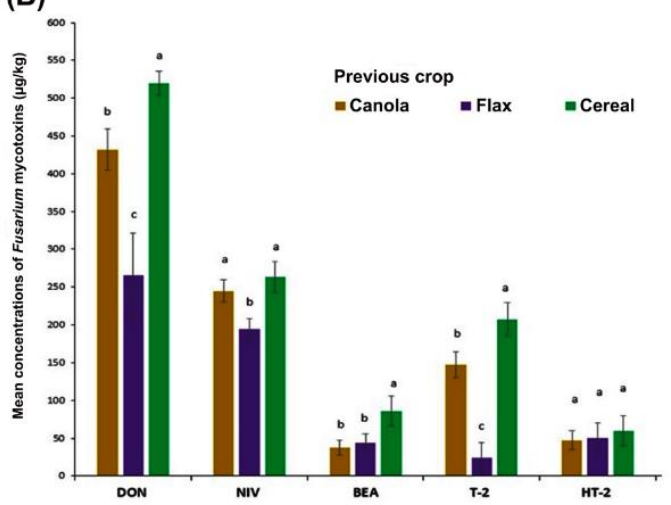

Figure 3. The effect of sampling location and crop rotation on the three-year mean concentration of Fusarium mycotoxins in oat samples from Manitoba. Bars (mean \pm standard error) followed by the same letter are not significantly different at $p=0.05$; (A) The samples locations were divided into fixed crops districts including CMB (Central Manitoba), SWMB (Southwest Manitoba), EMB (Eastern Manitoba), NVMB (Northwest Manitoba), and INMB (Interlake Manitoba). (B) The effect of previous crop on Fusarium mycotoxin content in Manitoba oat samples, collected in 2016, 2017, and 2018.

The concatenated nucleotide sequences of genes encoding a Translation elongation factor 1-alpha (Tef-1 $\alpha$ ), a P450 oxygenase (Tri1), and a trichothecene 3-O-esterase (Tri8) were used to infer phylogenetic relationships among 95 F. poae strains collected in Manitoba using the Maximum Likelihood (ML) method. The results of the phylogenetic analysis indicated that all F. poae strains belonged to a monophyletic lineage (Figure 4). With a strong bootstrap value support $(>75 \%)$, the consensus tree from ML analysis suggested four groups of $F$. poae strains. No clear correlation was evident between the grouping of these F. poae strains and sampling locations or previous hosts.

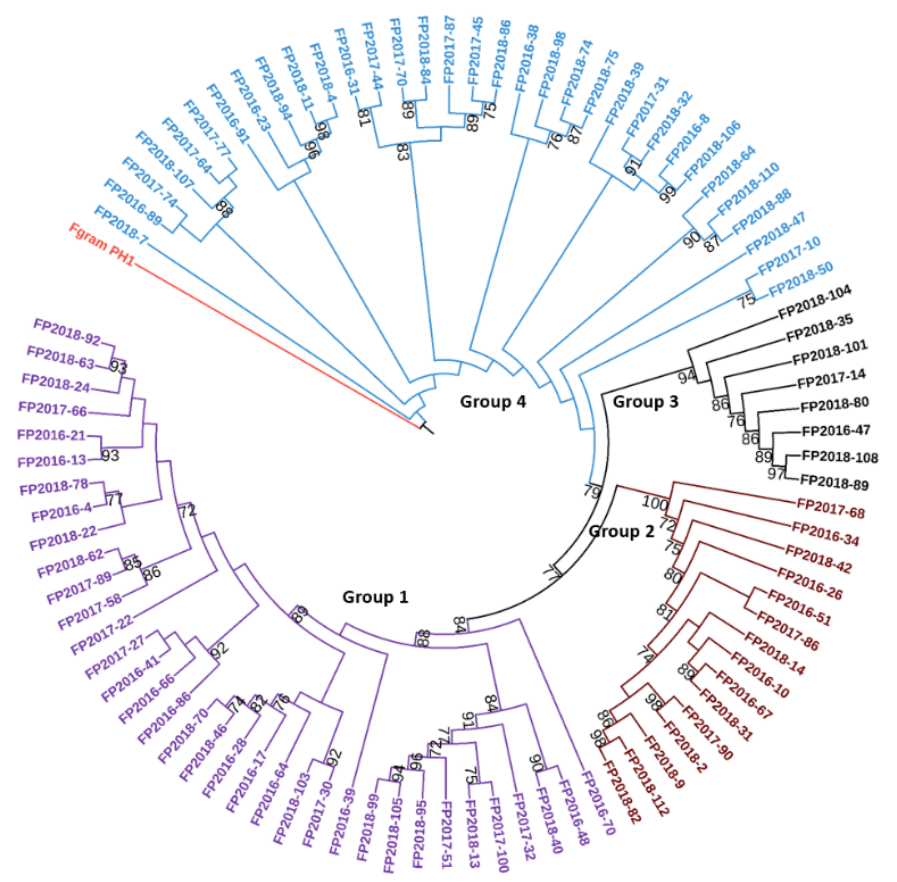

Figure 4. Maximum likelihood phylogenetic tree of 95 F. poae strains collected in Manitoba. The phylogenetic tree was inferred from the concatenated sequences of Tef- $1 \alpha$, Tri1, and Tri8 genes. Relevant bootstrap values (expressed as a percentage of 1000 replicates) are shown at branch points. The concatenated sequence of F. graminearum strain PH1 obtained from GenBank was treated as the outgroup. 


\section{Discussion}

This study investigated the Fusarium species complex associated with FHB on oat in Manitoba. The results show FHB is common on oat in Manitoba, with F. poae and F. graminearum being the two most commonly isolated species. In Manitoba, oat is grown in the same areas as wheat and barley, for which F. graminearum is the predominant Fusarium species found in Canada [8,10]; therefore, it is not surprising that F. graminearum is commonly isolated from oat grains. F. graminearum strains with both 3-ADON and $15-A D O N$ chemotypes were detected in oat samples, with 3-ADON strains found at a higher frequency. This pattern is comparable to the chemotype structures of F. graminearum previously reported in wheat. Prior to 1994, F. graminearum strains with the 15-ADON chemotype were the principal pathogen causing FHB in wheat in North America; however, a shift to F. graminearum strains with the 3-ADON chemotype was documented between 1998 and 2004 [24]. Several studies show a higher percentage of F. graminearum strains with 3-ADON vs. 15-ADON chemotypes in wheat from Western Canada [24-26]. Ward et al. [27] hypothesize that Eastern Canada was the original point of entry for F. graminearum 3-ADON populations in North America, followed by a spread into Western Canada and the upper Midwest of the United States. The drivers of the shifts in F. graminearum chemotype are not known but may be influenced by environmental conditions, host distribution, and various agricultural practices [28].

On wheat, F. poae is often considered a weakly pathogenic species. It is long thought that $F$. poae may infect and grow superficially but does not proliferate beyond infection sites $[29,30]$. Our study shows a higher concentration of $F$. poae DNA in oat grains than F. graminearum DNA. This indicates F. poae is well established on oat under field conditions. To date, information regarding the pathogenicity of $F$. poae on oat and the mechanism by which it interacts with other Fusarium species during infection has been limited. F. poae requires dry and warm conditions of around $25{ }^{\circ} \mathrm{C}$ for optimum growth and infection. In contrast, F. graminearum infection is often associated with prolonged wet and warm conditions during anthesis [31]. Environment parameters may differentially impact the success of these Fusarium pathogens on oat. Another possibility is that F. poae has a competitive advantage when it co-occurs with other Fusarium species during the infection. Ameye et al. [32] demonstrated that the volatile organic compounds emitted by perennial ryegrass (Lolium perenne L.) infected with F. poae could protect the plants against F. graminearum by priming for jasmonic acid (JA)-dependent defence. More recently, Tan et al. [33] showed that the expression of genes encoding isochorismate synthases and lipoxygenases is upregulated during the asymptomatic infection of F. poae on wheat; they hypothesize F. poae could hamper a subsequent F. graminearum infection by inducing a host defence response. Additionally, there is evidence suggesting that F. poae is more resistant to ergosterol biosynthesis-inhibiting azole fungicides than F. graminearum [34]. The application of azole fungicides leads to an increased share of $F$. poae in the FHB population at the expense of F. graminearum in the field [23]. Thus, the selective pressure exerted by the extensive use of certain fungicides may also contribute to the predominance of F. poae on oat.

Deoxynivalenol was one of the most prevalent mycotoxins in oat from the present study, mainly associated with the infection caused by F. graminearum. Similarly, Gräfenhan et al. [35] demonstrated that DON is the most frequently detected mycotoxin in oat from Western Canada. In a more recent survey of FHB on oat in Eastern and Western Canada, DON was commonly detected in oat grains from these regions [36]. In Canada, the maximum limits for DON in uncleaned soft wheat are 2000 and 1000 ppb for staple foods and infant foods, respectively (https: / / www.grainscanada.gc.ca/en/about-us/consultations / 2019/falling-number-don.html, accessed 10 July 2021). The European Commission has set $1750 \mathrm{ppb}$ as the maximum limit for DON in unprocessed oat [37]. Oat samples from this study from both 2016 and 2017 exceed these DON concentration limits; however, sampling focused on FHB-infected spikes. Oats grown in Canada are mainly used for animal feed and human consumption, so FHB monitoring is also important in oat to reduce the threat of F. graminearum and DON to oat industries in Canada. 
Nivalenol was found to be a common contaminant in oat from all sampling districts. This result is in agreement with studies of Tittlemier et al. [36] and Campbell et al. [38], in which NIV was detected second only to levels of DON in oat grains collected from Western Canada. DON and NIV differ in their chemical structure; NIV has a hydroxyl group instead of hydrogen at the $\mathrm{C} 4$ position, increasing its toxicity to animals and humans compared to DON [39,40]. Additionally, several studies indicate that the co-occurrence of DON and NIV will synergistically affect their cytotoxicity [41,42]. The present study did not find any F. graminearum strains with the NIV chemotype in oat samples, but F. poae strains with the NIV chemotype were commonly detected. The concentrations of NIV and F. poae DNA in oat grains are highly correlated. Therefore, we conclude that F. poae is the main contributor of NIV in these oat samples from Manitoba. Similarly, Yli-Mattila et al. [43] and Schöneberg et al. [2] show high correlations between F. poae DNA and NIV levels in cereal grains. F. poae strains producing NIV in oat grains are concerning because testing for NIV is not routinely conducted at mills or elevators in Canada at present. Our study shows the importance of testing for NIV in naturally infected oat grains and a more extensive study on the importance of F. poae in Fusarium species complex affecting oats.

In European countries, HT-2/T-2 are the predominant mycotoxins found in oat grains, and $F$. langsethiae is the main contributor [2,44]. In this study, mean levels of T-2/HT-2 were much lower than those of DON and NIV. To date, F. langsethiae has not been identified in Canada to the best of the authors' knowledge. We observed a strong correlation between the concentration of $F$. sporotrichioides DNA and T-2/HT-2, indicating F. sporotrichioides is likely the primary producer of T-2/HT-2 in Manitoba oats. The Canadian Food Inspection Agency has recommended limiting the intake of HT-2 to $0.1 \mathrm{ppm}$ for cattle and poultry; the recommended tolerance level for T- 2 is $<1 \mathrm{ppm}$ (https: / inspection.canada.ca, accessed 10 July 2021). A few samples from 2016 had T-2 and/or HT-2 levels above $1000 \mu \mathrm{g} / \mathrm{kg}$. With FHB becoming a severe issue for oat in Canada in recent years, closely monitoring the levels of T-2 and HT-2 in naturally infected oat grains will be very important.

The ANOVA revealed a significant impact of sampling location on mycotoxin levels in oat. Several studies report significant variation in DON concentrations among grain samples collected from different regions of Canada. Environmental factors during anthesis, such as temperature and precipitation, can significantly impact the severity of FHB and the level of DON $[6,38,45]$. It is likely that higher mycotoxin concentrations in oat samples from $\mathrm{CMB}$, SWMB, and $\mathrm{EMB}$ are due to the localized climate in these regions, which were more conducive for the infection of Fusarium pathogen, such as the extended period of rainfall during the stage of anthesis. Other factors could also impact mycotoxin levels in oat, such as seeding date, resistance in oat cultivars, and timing of fungicide applications.

Crop rotation also impacts mycotoxin levels in oat grains. In our study, the cereals-oat rotation resulted in higher mycotoxin levels in oat grains than that with canola-oat or flaxoat rotations. Similarly, Pageau et al. [46] showed that the highest DON content in barley occurs when cereals rather than a dry pea are seeded in crop rotation. The preceding crop likely affects FHB epidemics by acting as a suitable host plant for Fusarium pathogens, i.e., increasing the amount of inoculum and producing large amounts of crop debris suitable for the saprophytic survival of these pathogens [47]. Our result indicates that crop rotation will have a significant impact on the management of FHB. Rotating away from cereals to non-host crops, including canola and pulses, could reduce the severity of FHB/mycotoxin contamination in oat by reducing the buildup of FHB infested crop residues from the previous growing season. We assessed the genetic variation of a set of $F$. poae strains collected in Manitoba using the concatenated sequence of Tef- $1 \alpha$, Tri1, and Tri8 genes. The phylogenetic analysis indicates all of these $F$. poae strains are part of a monophyletic lineage. This result is in line with previous reports for F. poae [48]. No correlation between sample location and sub-grouping of F. poae strains was observed (Table S3). Similarly, Dinolfo et al. [49] and Vanheule et al. [50] demonstrate that the clustering of $F$. poae strains based on ISSR and AFLP markers had no clear correlation with geographic origins. On the 
other hand, Vogelgsang et al. [51] characterize two groups of $F$. poae strains from distinct geographic areas within Switzerland using microsatellite markers. F. poae is now known to possess four core chromosomes and several supernumerary chromosomes [52]. The discrepancies among the results of the above studies may be due to the different types of genetic markers used, which target different regions of the F. poae genome. Witte et al. [53] show an Eastern Canadian F. poae strain (DAOMC 252244, Fp157) contains four core chromosomes and seven additional contigs associated with accessory chromosomes that harbour a functional biosynthetic apicidin synthetase (APS1) gene cluster, a hemorrhagic factor for toxin-producing fungi [54]. Such toxin potentiality of $F$. poae calls for further exploration of APS-producing populations in Western Canadian oat production systems.

In Fusarium species, the production of trichothecenes is a result of the expression of the Tri 12-gene cluster and the unlinked Tri1 and Tri101 genes. In F. graminearum, variations in Tri1 and Tri8 are associated with the production of different trichothecene chemotypes [55,56]. Vanheule et al. [50] report that the Tri1 locus in F. poae is highly variable with mostly synonymous mutations, with two main Tri1 types identified in a collection of European F. poae strains. In this study, we observed reasonably high intra-species variability of Tri1 and Tri8 in F. poae strains from Manitoba. Whether the variability of these two genes will affect the toxigenic potential of $F$. poae is currently unclear and is an interesting question that merits further investigation. The preliminary phylogenetic analysis conducted in this study serves as an essential addition to existing knowledge on the diversity of the $F$. poae population in Manitoba. The results will facilitate the selection of $F$. poae strains for future genomic studies to better understand this emerging pathogen's diversity, genomics, and toxic potential.

\section{Materials and Methods}

\subsection{Oat Sample Collections}

A total of 168 oat fields (43, 60, and 65 in 2016, 2017, and 2018, respectively) in Manitoba were surveyed for FHB between July 18 and August 5 of each year. The field locations were divided into five crop districts: (1) Central Manitoba (CMB), (2) Southwest Manitoba (SWMB), (3) Eastern Manitoba (EMB), (4) Northwest Manitoba (NWMB), and (5) Interlake Manitoba (INMB) (Supplementary Figure S1). The oat fields were surveyed between the late milk growth stage (BBCH 77) and full maturity $(\mathrm{BBCH} 89)$. Fields were accessed approximately every $20-25 \mathrm{~km}$ along the survey routes, depending on crop availability and accessibility. On average, 40-60 FHB infected spikes/panicles were randomly collected from each oat field and stored in paper envelopes. For each sampling location, information on the preceding crop was also collected.

\subsection{Isolation and Identification of Fusarium Pathogens}

For each field, 50 oat seeds were randomly selected and used to isolate Fusarium pathogens using Potato Dextrose Agar (PDA, Thermo Fisher, Mississauga, ON, Canada) media. Before plating, oat seeds were surface-sterilized for $90 \mathrm{~s}$ in $0.3 \%$ sodium hypochlorite, rinsed twice with distilled water, and then dried for $5 \mathrm{~min}$ at the room temperature. The PDA plates were incubated for 5 days at room temperature $\left(20-25^{\circ} \mathrm{C}\right)$ in the dark. A total of 8400 oat grains over 3 years were subjected to the identification of Fusarium species. The identification of Fusarium pathogens was performed using compound and dissecting microscopy based on conidia morphology [57].

\subsection{Extraction and Quantification of Fusarium Genomic DNA in Oat Grains}

A subsample of $20 \mathrm{~g}$ oat grains per field was ground with an oat grinder (Retsch ZM 200, Scientific Inc. Newtown, PA, USA). One-gram grain flour was used to extract DNA using the QIAGEN DNeasy Mini Kit (QIAGEN Mississauga, ON, Canada) following the manufactures' procedure.

Quantitative PCR was used to determine the abundance of Fusarium genomic DNA in oat using a CFX96 ${ }^{\mathrm{TM}}$ Real-Time PCR Detector System (BioRad, Mississauga, ON, Canada). 
All standards and the negative control (double-distilled water) were run in triplicate. Primers, based on the elongation factor $1 \alpha(T e f-1 \alpha)$ gene for three Fusarium species (F. graminearum, F. poae, and F. sporotrichioides), were used to quantify Fusarium genomic DNA in oat grains (Table S1). The PCR was carried out in a total volume of $20 \mu \mathrm{L}$, consisting of $10 \mu \mathrm{L}$ of SsoFast EvaGreen ${ }^{\circledR}$ PCR Master Mix (BioRad), $1 \mu \mathrm{L}$ of each primer, $6 \mu \mathrm{L}$ of double-distilled water, and $2 \mu \mathrm{L}$ of template DNA with a 37-cycle threshold (Ct) detection limit. PCR conditions were as follows: initial preheating at $98^{\circ} \mathrm{C}$ for $2 \mathrm{~min} ; 40$ cycles of $95^{\circ} \mathrm{C}$ for $15 \mathrm{~s}$ and $62{ }^{\circ} \mathrm{C}$ for $1 \mathrm{~min}$; and dissociation curve analysis at 60 to $95^{\circ} \mathrm{C}$. Six technical replicates were performed for each sample.

\subsection{Identification of Fusarium Chemotypes}

Multiplex PCR was performed to determine 3-ADON, 15-ADON, and NIV chemotypes with specific primers (Table S1). PCR assays were completed using the following cycle parameters: initial denaturing step at $95^{\circ} \mathrm{C}$ for $5 \mathrm{~min} ; 30$ cycles at $95^{\circ} \mathrm{C}$ for $30 \mathrm{~s}, 50^{\circ} \mathrm{C}$ for $30 \mathrm{~s}$, and $72{ }^{\circ} \mathrm{C}$ for $2 \mathrm{~min}$; and a final extension step at $72{ }^{\circ} \mathrm{C}$ for $3 \mathrm{~min}$. PCR amplicons were separated on $2 \%$ agarose gels in the $1 \times$ TAE buffer and stained with GelRed (Biotium, Mississauga, ON, Canada). Gel images were scanned into Gel Doc ${ }^{\mathrm{TM}} \mathrm{EZ}$ Imager (BioRad). Percentages of oat fields infected with Fusarium pathogens with 3-ADON, 15-ADON, and NIV chemotypes were recorded.

\subsection{Detection and Quantification of Mycotoxins}

Oat grain samples were analyzed for 11 Fusarium mycotoxins including DON, DAS, NIV, BEA, HT-2, T-2, moniliformin (MON), enniatin A (ENN A), enniatin A1 (ENN A1), enniatin B (ENN B), and enniatin B1 (ENN B1) at the Mycotoxin Lab (Morden Research and Development Centre, AAFC, MB, Canada). Ground oat samples (1 g) were used to extract mycotoxins using a mixture of solvent $(10 \mathrm{~mL}$, acetonitrile $(75 \%)$ : methanol $(10 \%)$ : water $(15 \%)$ in a $10 \mathrm{~mL}$ flat-bottomed tube. Sample-solvent mixture was mixed thoroughly by inversion, followed by sonication $(30 \mathrm{~min})$. The tubes were then loaded onto a rotatory shaker and extracted for $90 \mathrm{~min}$ at $40 \mathrm{rpm}$. The samples were centrifuged $(4000 \times g$ for $30 \mathrm{~min}$ ) to separate the extract from the ground material, and the supernatant was filtered through a $0.2 \mu \mathrm{m}$ nylon syringe filter (ThermoFisher, Mississauga, ON, Canada) into a clean $10 \mathrm{~mL}$ flat-bottomed tube. The filtered extracts were dried under a gentle stream of nitrogen gas in a nitrogen evaporator (RapidVap Labconco, Kansas city, MO, USA) at 100\% speed for $90 \mathrm{~min}$ at $70{ }^{\circ} \mathrm{C}$. Each dried-sample extract was re-suspended in $1 \mathrm{~mL}$ of 50:50 water $+0.1 \%$ formic acid $+5 \mathrm{mM}$ ammonium formate): methanol $+0.1 \%$ formic acid $+5 \mathrm{mM}$ ammonium formate, vortexed, and transferred into amber liquid chromatography (LC) vial before analyzing using a high-resolution mass spectrometer (Orbitrap ID-X Tribrid Mass Spectrometer, Thermo Fisher Scientific Inc., Mississauga, ON, Canada) coupled with ultra-high performance liquid chromatography (UHPLC-HRMS, Vanquish, Thermo Fisher Scientific, Mississauga, ON, Canada). Separation of various mycotoxins was performed using a reverse-phase C18 core-shell silica column (particle size $1.7 \mu \mathrm{m}, 100 \times 2.1 \mathrm{~mm}$, Kinetex, Phenomenex, CA, USA) held at $35^{\circ} \mathrm{C}$. Gradient elution was achieved with $100 \%$ water (mobile phase A) and 100\% methanol (mobile phase B) with both phases containing $0.1 \%$ formic acid and $5 \mathrm{mM}$ ammonium formate and at a flow rate of $0.2 \mathrm{~mL} \mathrm{~min}^{-1}$ in 20 min runs. Retention times are identified in Table S2. Heated-electrospray (H-ESI) was used to achieve a steady state of electrospray from the chromatographic separation column. The HRMS was operated in positive mode at 120,000 orbitrap resolution for precursor ion mass-to-charge $(\mathrm{m} / \mathrm{z})$ with mass tolerance of $\pm 5 \mathrm{ppm}$ while fragment ion mass spectra were acquired at 30,000 resolution. Precursor and fragment ion $\mathrm{m} / \mathrm{z}$ values are noted in Table S2. Fragmentation was achieved in the higher energy collision-induced dissociation (HCD) with stepped collision energies $(15,20$, and $25 \%)$. The parent mass was used for analyte quantification, and fragment ions were used for analyte confirmation.

Spiked reference material was extracted with each batch of samples and was extracted simultaneously. The recoveries for various mycotoxin standards (Sigma-Aldrich, Oakville, 
ON, Canada) are noted in Table S2. The limit of quantification (LOQ) and limit of detection (LOD) for various mycotoxins were 50 and $10 \mathrm{ppb}$, respectively.

\subsection{Sequencing of F. poae Tef-1 $\alpha$, Tri1, and Tri8 Genes}

DNA was extracted from mycelium of F. poae using the QIAGEN DNeasy Mini Kit. Sequences of Tef- $1 \alpha$, Tri1, and Tri 8 were amplified directly from $F$. poae genomic DNA using the primer sets listed in Table S1. Primers were designed based on the consensus of previously published F. poae genome sequences [53]. PCR reactions were performed with a C1000 Touch ${ }^{\mathrm{TM}}$ Thermal Cycler system (BioRad) in a volume of $25 \mu \mathrm{L}$ containing $2.5 \mu \mathrm{L}$ of $10 \times$ PCR buffer, $15.88 \mu \mathrm{L}$ of water, $2 \mu \mathrm{L}$ of dNTP mix $(2.5 \mathrm{mM}), 1 \mu \mathrm{L}$ of each primer $(10 \mathrm{pmol}), 0.125 \mu \mathrm{L}$ of Taq polymerase $(5 \mathrm{U} / \mu \mathrm{L})$, and $2.5 \mu \mathrm{L}$ of template DNA $(100 \mathrm{ng} / \mu \mathrm{L})$. Amplification was carried out using an annealing temperature of $56{ }^{\circ} \mathrm{C}$ for $30 \mathrm{~s}$. The PCR assay was completed using the following cycle parameters: initial denaturing step at $94{ }^{\circ} \mathrm{C}$ for $15 \mathrm{~min} ; 30$ cycles at $95^{\circ} \mathrm{C}$ for $30 \mathrm{~s}, 50{ }^{\circ} \mathrm{C}$ for $30 \mathrm{~s}$, and $72{ }^{\circ} \mathrm{C}$ for $90 \mathrm{~s}$; and a final extension step at $72{ }^{\circ} \mathrm{C}$ for $3 \mathrm{~min}$. The PCR products were separated electrophoretically on $1.5 \%$ agarose gels in $1 \times$ TAE buffer and stained with gel Red (Biotium). The amplified bands were cut under UV light (UVITEC, Rugby, UK), and purification of the gene (PCR amplicons) was performed using Gel Extraction Kits (Qiagen) following the manufacturer's protocols. The concentration of the products was checked using a NanoDrop 2000 spectrophotometer (ThermoFisher, Wilmington, NC, USA). The cleaned PCR amplicons were sequenced using Sanger sequencing protocols (ABI 3730xl DNA sequencers, National Research Council, Saskatoon, SK, Canada).

\subsection{Phylogenetic Analysis of F. poae Strains Based on Tri1, Tri8, and Tef-1 $\alpha$ Genes}

The raw Sanger sequences were processed using MEGAX to clean ambiguous nucleotides (average quality $>50$ ). Excessively long and short homopolymer, low-quality, and chimeric sequences were removed from the dataset. The alignments of Tef- $1 \alpha$, Tri1, and Tri8 were created using MUSCLE [58] with default settings. TrimAI [59] was used to trim the alignments and remove positions with gaps in $10 \%$ or more of the sequences. The concatenated sequence of Tef- $1 \alpha$, Tri1, and Tri8 of F. graminearum PH-1 (assembly ASM24013v3) was also created using MEGAX and included as an outgroup. A partitioned file stating the positions of individual genes in the concatenated alignment was created. IQTree (version 1.6.12) was used to find the best substitution model for each partition (-m MFP) and infer a consensus tree using maximum likelihood and ultrafast bootstrapping $(n=1000)$.

\subsection{Statistical Analysis}

The homogeneity of data ( $n=168$ oat fields/samples) was verified using the KolmogorovSmirnov test of normality, which measured the divergence of the field sample distribution. The skewness and kurtosis were determined and plotted for each year of survey data to determine whether the data distribution was normal. The data were transformed (log, square root, arcsine), and outliers were removed (extreme low and high values) when necessary. One-way analysis of variance (ANOVA) (Version 9.4, SAS Institute, Cary, NC, USA) was used to determine the significance of survey years, geographical field locations/crop districts, and preceding crops (crop rotation) on the concentration of five mycotoxins (DON, NIV, BEA, HT-2, T-2). The Least Significant Difference (LSD) test was used to compare the means of different treatment groups. Principal component analysis (PCA) was performed to analyze the correlation between DNA concentrations of three Fusarium species (F. poae, F. graminearum, F. sporotrichioides) and five main Fusarium mycotoxins (DON, NIV, BEA, HT-2, T-2) using SAS software statistics.

Supplementary Materials: The following are available online at https:/ /www.mdpi.com/article/10 .3390 /toxins13090670/s1, Table S1: Fusarium species/chemotype-specific primers with amplicon size and sequences, Table S2: Precursor and product ions $(\mathrm{m} / \mathrm{z})$, retention times, and recoveries of various mycotoxins, Table S3: List of $F$. poae strains and corresponding crop districts/location of isolates and 
rotational crop varieties in Manitoba (2016-2018). Group designation was based on Tef-1 $\alpha$ - Tri1-Tri8 phylogenetic analysis.

Author Contributions: All authors have read and agreed to the published version of the manuscript. Conceptualization, M.N.I. and X.W.; methodology, X.W., F.D., L.J.H., and S.S.; software, M.N.I.; validation, M.N.I. and X.W.; formal analysis, M.N.I., S.S., and X.W.; investigation, M.B. and M.T.; resources, M.B. and M.T.; data curation, M.N.I.; writing-original draft preparation, M.N.I. and X.W.; writing-review and editing, F.D., W.G.D.F., L.J.H., and S.S.; visualization, X.W.; supervision, X.W.; project administration, X.W.; funding acquisition, X.W.

Funding: This work was funded by the Western Grains Research Foundation (AGR1856B), Canada and Agriculture and Agri-Food Canada grants awarded to X.W.

Informed Consent Statement: Not applicable.

Data Availability Statement: Not applicable.

Acknowledgments: The authors acknowledge and thank Micaela Gray for her role in mycotoxin analysis and technical support and Meconnen Beyene for technical and logistical support related to preparing and analyzing survey grain samples.

Conflicts of Interest: The authors declare no conflict of interest.

\section{References}

1. Strychar, R. World oat production, trade, and usage. In Oats: Chemistry and Technology, 2nd ed.; American Association of Cereal Chemists, Inc. (AACC): St. Paul, MN, USA, 2016; pp. 1-10.

2. Schöneberg, T.; Martin, C.; Wettstein, F.E.; Bucheli, T.D.; Mascher, F.; Bertossa, M.; Musa, T.; Keller, B.; Vogelgsang, S. Fusarium and mycotoxin spectra in Swiss barley are affected by various cropping techniques. Food Addit. Contam. Part A Chem. Anal. Control Expo. Risk Assess. 2016, 33, 1608-1619. [CrossRef]

3. Bjørnstad, A.; Skinnes, H. Resistance to Fusarium infection in oats (Avena sativa L.). Cereal Res. Commun. 2008, 36, 57-62. [CrossRef]

4. Tekauz, A.; Mitchell Fetch, J.; Rossnagel, B.G.; Savard, M.E. Progress in assessing the impact of Fusarium head blight on oat in western Canada and screening Avena germplasm for resistance. Cereal Res. Commun. 2008, 36 (Suppl. 6), 49-56. [CrossRef]

5. Tekauz, A.; McCallum, B.; Ames, N.; Fetch, J.M. Fusarium head blight of oat-Current status in western Canada. Can. J. Plant Pathol. 2004, 26, 473-479. [CrossRef]

6. Clear, R.M.; Patrick, S.K.; Gaba, D. Prevalence of fungi and fusariotoxins on oat seed from western Canada, 1995-1997. Can. J. Plant Pathol. 2000, 22, 310-314. [CrossRef]

7. Tamburic-Ilincic, L. Fusarium species and mycotoxins associated with oat in southwestern Ontario, Canada. Can. J. Plant Sci. 2010, 90, 211-216. [CrossRef]

8. Xue, A.G.; Chen, Y.H.; Seifert, K.; Guo, W.; Blackwell, B.A.; Harris, L.J.; Overy, D.P. Prevalence of Fusarium species causing head blight of spring wheat, barley and oat in Ontario during 2001-2017. Can. J. Plant Pathol. 2019, 41, 392-402. [CrossRef]

9. Parry, D.W.; Jenkinson, P.; McLeod, L. Fusarium ear blight (SCAB) in small-grain cereals-A review. Plant Pathol. 2007, 44, 207-238. [CrossRef]

10. Gilbert, J.; Tekauz, A. Review: Recent developments in research on fusarium head blight of wheat in Canada. Can. J. Plant Pathol. 2000, 22, 1-8. [CrossRef]

11. Rohácik, T.; Hudec, K. Influence of agro-environmental factors on fusarium infestation and population structure in wheat kernels. Ann. Agric. Environ. Med. 2005, 12, 39-45.

12. Stenglein, S. Fusarium poae: A pathogen that needs more attention. J. Plant Pathol. 2009, 91, 25-36. [CrossRef]

13. Foroud, N.A.; Baines, D.; Gagkaeva, T.Y.; Thakor, N.; Badea, A.; Steiner, B.; Bürstmayr, M.; Bürstmayr, H. Trichothecenes in gereal grains-An update. Toxins 2019, 11, 634. [CrossRef] [PubMed]

14. Nogueira, M.S.; Decundo, J.; Martinez, M.; Dieguez, S.N.; Moreyra, F.; Moreno, M.V.; Stenglein, S.A. Natural contamination with mycotoxins produced by Fusarium graminearum and Fusarium poae in malting barley in Argentina. Toxins 2018, 10, 78. [CrossRef] [PubMed]

15. Dinolfo, M.J.; Stenglein, S. Fusarium poae and mycotoxins: Potential risk for consumers. Bol. De La Soc. Argent. De Bot. 2014, 49, 5-20. [CrossRef]

16. Stenglein, S.A.; Dinolfo, M.I.; Barros, G.; Bongiorno, F.; Chulze, S.N.; Moreno, M.V. Fusarium poae pathogenicity and mycotoxin accumulation on selected wheat and barley genotypes at a single location in Argentina. Plant Dis. 2014, 98, 1733-1738. [CrossRef] [PubMed]

17. Nagashima, H. Deoxynivalenol and nivalenol toxicities in cultured cells: A review of comparative studies. Food Saf. 2018, 6, 51-57. [CrossRef]

18. Yagen, B.; Joffe, A.Z. Screeing of toxic isolates of Fusarium poae and Fusarium sporotrichiodes involved in causing alimentary toxic aleukia. Appl. Environ. Microbiol. 1976, 32, 423-427. [CrossRef]

19. Foroud, N.A.; Eudes, F. Trichothecenes in cereal grains. Int. J. Mol. Sci. 2009, 10, 147-173. [CrossRef] 
20. Tekle, S.; Dill-Macky, R.; Skinnes, H.; Tronsmo, A.M.; Bjcirnstad, C. Infection process of Fusarium graminearum in oats (Avena sativa L.). Eur. J. Plant Pathol. 2012, 132, 431-442. [CrossRef]

21. Tini, F.; Beccari, G.; Onofri, A.; Ciavatta, E.; Gardiner, D.M.; Covarelli, L. Fungicides may have differential efficacies towards the main causal agents of Fusarium head blight of wheat. Pest Manag. Sci. 2020, 76, 3738-3748. [CrossRef]

22. Tan, J.; De Zutter, N.; De Saeger, S.; De Boevre, M.; Tran, T.M.; van der Lee, T.; Waalwijk, C.; Willems, A.; Vandamme, P.; Ameye, M.J.F.I.P.S. Presence of the weakly pathogenic Fusarium poae in the Fusarium head blight disease complex hampers biocontrol and chemical control of the virulent Fusarium graminearum Pathogen. Front. Plant Sci. 2021, 12, 216. [CrossRef]

23. Audenaert, K.; Landschoot, S.; Vanheule, A.; Waegeman, W.; De Baets, B.; Haesaert, G. Impact of fungicide timing on the composition of the Fusarium head blight disease complex and the presence of deoxynivalenol (DON) in wheat. In FungicidesBeneficial and Harmful Aspects; Thajuddin, N., Ed.; IntechOpen: London, UK, 2011; pp. 79-98.

24. Gilbert, J.; Clear, R.M.; Ward, T.J.; Gaba, D.; Tekauz, A.; Turkington, T.K.; Woods, S.M.; Nowicki, T.; O’Donnell, K. Relative aggressiveness and production of 3- or 15-acetyl deoxynivalenol and deoxynivalenol by Fusarium graminearum in spring wheat. Can. J. Plant Pathol. 2010, 32, 146-152. [CrossRef]

25. Amarasinghe, C.C.; Tittlemier, S.A.; Fernando, W.G.D. Nivalenol-producing Fusarium cerealis associated with fusarium head blight in winter wheat in Manitoba, Canada. Plant Pathol. 2015, 64, 988-995. [CrossRef]

26. Amarasinghe, C.; Tamburic-Ilincic, L.; Gilbert, J.; Brûlé-Babel, A.L.; Dilantha Fernando, W. Evaluation of different fungicides for control of Fusarium head blight in wheat inoculated with 3-ADON and 15-ADON chemotypes of Fusarium graminearum in Canada. Can. J. Plant Pathol. 2013, 35, 200-208. [CrossRef]

27. Ward, T.J.; Clear, R.M.; Rooney, A.P.; O’Donnell, K.; Gaba, D.; Patrick, S.; Starkey, D.E.; Gilbert, J.; Geiser, D.M.; Nowicki, T.W. An adaptive evolutionary shift in Fusarium head blight pathogen populations is driving the rapid spread of more toxigenic Fusarium graminearum in North America. Fungal Genet. Biol. 2008, 45, 473-484. [CrossRef]

28. Valverde-Bogantes, E.; Bianchini, A.; Herr, J.R.; Rose, D.J.; Wegulo, S.N.; Hallen-Adams, H.E. Recent population changes of Fusarium head blight pathogens: Drivers and implications. Can. J. Plant Pathol. 2020, 42, 315-329. [CrossRef]

29. Xue, A.G.; Chen, Y.H.; Marchand, G.; Guo, W.; Ren, C.Z.; Savard, M.; McElroy, R.B. Timing of inoculation and Fusarium species affect the severity of Fusarium head blight on oat. Can. J. Plant Sci. 2015, 95, 517-524. [CrossRef]

30. Beccari, G.; Arellano, C.; Covarelli, L.; Tini, F.; Sulyok, M.; Cowger, C. Effect of wheat infection timing on Fusarium head blight causal agents and secondary metabolites in grain. Int. J. Food Microbiol. 2019, 290, 214-225. [CrossRef] [PubMed]

31. Xu, X.M.; Nicholson, P.; Thomsett, M.A.; Simpson, D.; Cooke, B.M.; Doohan, F.M.; Brennan, J.; Monaghan, S.; Moretti, A.; Mule, G.; et al. Relationship between the fungal complex causing Fusarium head blight of wheat and environmental conditions. Phytopathology 2008, 98, 69-78. [CrossRef]

32. Ameye, M.; Audenaert, K.; De Zutter, N.; Steppe, K.; Vanhaecke, L.; De Vleesschauwer, D.; Haesaert, G.; Smagghe, G. Priming of wheat with the green leaf volatile Z-3-hexenyl acetate enhances defense against Fusarium graminearum but boosts deoxynivalenol production. Plant Physiol. 2015, 167, 1671-1684. [CrossRef] [PubMed]

33. Tan, J.; Ameye, M.; Landschoot, S.; De Zutter, N.; De Saeger, S.; De Boevre, M.; Abdallah, M.F.; Van der Lee, T.; Waalwijk, C.; Audenaert, K. At the scene of the crime: New insights into the role of weakly pathogenic members of the fusarium head blight disease complex. Mol. Plant Pathol. 2020, 21, 1559-1572. [CrossRef]

34. Gao, T.; Zhou, H.; Zhou, W.; Hu, L.; Chen, J.; Shi, Z.Q. The fungicidal activity of thymol against Fusarium graminearum via inducing lipid peroxidation and disrupting ergosterol biosynthesis. Molecules 2016, 21, 770. [CrossRef]

35. Gräfenhan, T.; Patrick, S.K.; Roscoe, M.; Trelka, R.; Gaba, D.; Chan, J.M.; McKendry, T.; Clear, R.M.; Tittlemier, S.A. Fusarium damage in cereal grains from Western Canada. 1. Phylogenetic analysis of moniliformin-producing Fusarium species and their natural occurrence in mycotoxin-contaminated wheat, oats, and rye. J. Agric. Food Chem. 2013, 61, 5425-5437. [CrossRef] [PubMed]

36. Tittlemier, S.A.; Blagden, R.; Chan, J.M.; Roscoe, M.; Pleskach, K. A multi-year survey of mycotoxins and ergosterol in Canadian oats. Mycotoxin Res. 2020, 36, 103-114. [CrossRef]

37. European Commission. Commission Regulation (EC) No 401/2006 of 23, Laying down the Methods of Sampling and Analysis for the Official Control of the Levels of Mycotoxins in Food Stuffs, February 2006; European Commission: Brussels, Belgium, 2006; Volume 70, pp. 12-34.

38. Campbell, H.; Choo, T.M.; Vigier, B.; Underhill, L. Mycotoxins in barley and oat samples from eastern Canada. Can. J. Plant Sci. 2000, 80, 977-980. [CrossRef]

39. Visconti, A.; Minervini, F.; Lucivero, G.; Gambatesa, V. Cytotoxic and immunotoxic effects of Fusarium mycotoxins using a rapid colorimetric bioassay. Mycopathologia 1991, 113, 181-186. [CrossRef]

40. Minervini, F.; Fornelli, F.; Flynn, K.M. Toxicity and apoptosis induced by the mycotoxins nivalenol, deoxynivalenol and fumonisin B1 in a human erythroleukemia cell line. Toxicol. Vitr. 2004, 18, 21-28. [CrossRef]

41. Yang, Y.X.; Yu, S.; Tan, Y.L.; Liu, N.; Wu, A. Individual and combined cytotoxic effects of co-occurring deoxynivalenol family mycotoxins on human gastric epithelial cells. Toxins 2017, 9, 96. [CrossRef] [PubMed]

42. Cheat, S.; Pinton, P.; Cossalter, A.; Cognie, J.; Vilariño, M.; Callu, P.; Raymond-Letron, I.; Oswald, I.P.; Kolf-Clauw, M. The mycotoxins deoxynivalenol and nivalenol show in vivo synergism on jejunum enterocytes apoptosis. Food Chem. Toxicol. 2016, 87, 45-54. [CrossRef] 
43. Yli-Mattila, T.; Paavanen-Huhtala, S.; Jestoi, M.; Parikka, P.; Hietaniemi, V.; Gagkaeva, T.; Sarlin, T.; Haikara, A.; Laaksonen, S.; Rizzo, A. Real-time PCR detection and quantification of Fusarium poae, F. graminearum, F. sporotrichioides and F. langsethiae in cereal grains in Finland and Russia. Arch. Phytopathol. Plant Prot. 2008, 41, 243-260. [CrossRef]

44. Martin, C.; Schöneberg, T.; Vogelgsang, S.; Mendes Ferreira, C.S.; Morisoli, R.; Bertossa, M.; Bucheli, T.D.; Mauch-Mani, B.; Mascher, F. Responses of oat grains to Fusarium poae and F. langsethiae Infections and mycotoxin contaminations. Toxins 2018, 10, 47. [CrossRef] [PubMed]

45. Martos, P.; Thompson, W.; Diaz, G. Multi residue mycotoxin analysis in wheat, barley, oats, rye and maize grain by highperformance liquid chromatography-tandem mass spectrometry. World Mycotoxin J. 2010, 3, 205-223. [CrossRef]

46. Pageau, D.; Lafond, J.; Lajeunesse, J.; Savard, M. Impact of previous cultivation and nitrogen fertilization on deoxynivalenol content in barley. Can. J. Plant Pathol. 2008, 30, 397-403. [CrossRef]

47. Beyer, M.; Klix, M.B.; Klink, H.; Verreet, J.A. Quantifying the effects of previous crop, tillage, cultivar and triazole fungicides on the deoxynivalenol content of wheat grain-A review. J. Plant Dis. Prot. 2006, 113, 241-246. [CrossRef]

48. Knutsen, A.K.; Torp, M.; Holst-Jensen, A. Phylogenetic analyses of the Fusarium poae, Fusarium sporotrichioides and Fusarium langsethiae species complex based on partial sequences of the translation elongation factor-1 alpha gene. Int. J. Food Microbiol. 2004, 95, 287-295. [CrossRef]

49. Dinolfo, M.I.; Stenglein, S.A.; Moreno, M.V.; Nicholson, P.; Jennings, P.; Salerno, G.L. ISSR markers detect high genetic variation among Fusarium poae isolates from Argentina and England. Eur. J. Plant Pathol. 2010, 127, 483-491. [CrossRef]

50. Vanheule, A.; De Boevre, M.; Moretti, A.; Scauflaire, J.; Munaut, F.; De Saeger, S.; Bekaert, B.; Haesaert, G.; Waalwijk, C.; van der Lee, T.; et al. Genetic divergence and chemotype diversity in the Fusarium head blight pathogen Fusarium poae. Toxins 2017, 9 , 255. [CrossRef]

51. Vogelgsang, S.; Enkerli, J.; Jenny, E.; Roffler, S.; Widmer, F. Characterization of Fusarium poae microsatellite markers on strains from Switzerland and other countries. J. Phytopathol. 2011, 159, 197-200. [CrossRef]

52. Vanheule, A.; Audenaert, K.; Warris, S.; van de Geest, H.; Schijlen, E.; Höfte, M.; De Saeger, S.; Haesaert, G.; Waalwijk, C.; van der Lee, T. Living apart together: Crosstalk between the core and supernumerary genomes in a fungal plant pathogen. BMC Genom. 2016, 17, 670. [CrossRef]

53. Witte, T.; Harris, L.J.; Nguyen, H.; Hermans, A.; Johnston, A.; Sproule, A.; Dettman, J.; Boddy, C.; Overy, D. Apicidin biosynthesis ss linked to accessory chromosomes in Fusarium poae isolates. BMC Genom. 2021, 22, 1-18. [CrossRef]

54. Abbas, H.K.; Mirocha, C.J. Isolation and purification of a hemorrhagic factor (wortmannin) from Fusarium oxysporum (N17B). Appl. Environ. Microbiol. 1988, 54, 1268-1274. [CrossRef] [PubMed]

55. Varga, E.; Wiesenberger, G.; Hametner, C.; Ward, T.J.; Dong, Y.; Schöfbeck, D.; McCormick, S.; Broz, K.; Stückler, R.; Schuhmacher, R.; et al. New tricks of an old enemy: Isolates of Fusarium graminearum produce a type A trichothecene mycotoxin. Environ. Microbiol. 2015, 17, 2588-2600. [CrossRef] [PubMed]

56. Alexander, N.J.; McCormick, S.P.; Waalwijk, C.; van der Lee, T.; Proctor, R.H. The genetic basis for 3-ADON and 15-ADON trichothecene chemotypes in Fusarium. Fungal Genet. Biol. 2011, 48, 485-495. [CrossRef] [PubMed]

57. Leslie, J.F.; Summerell, B.A. The Fusarium Laboratory Manual, 1st ed.; Blackwell Pub.: Ames, IA, USA, 2006.

58. Edgar, R.C. MUSCLE: Multiple sequence alignment with high accuracy and high throughput. Nucleic Acids Res. 2004, 32, 1792-1797. [CrossRef] [PubMed]

59. Capella-Gutiérrez, S.; Silla-Martínez, J.M.; Gabaldón, T. trimAl: A tool for automated alignment trimming in large-scale phylogenetic analyses. Bioinformatics 2009, 25, 1972-1973. [CrossRef] [PubMed] 